Check for updates

Cite this: RSC Adv., 2017, 7, 49838

\title{
Synergistic catalytic effects of visible light and graphene on bioleaching of chalcopyrite
}

\author{
Baojun Yang, ${ }^{a}$ Min Gan, ${ }^{a}$ Wen Luo, ${ }^{b}$ Shuang Zhou, ${ }^{c}$ Pan Lei, ${ }^{a}$ Jian Zeng, ${ }^{a}$ Wei Sun, ${ }^{a}$ \\ Jianyu Zhu (D) ${ }^{* a}$ and Yuehua $\mathrm{Hu}^{* a}$
}

The effects of graphene and visible light on chalcopyrite bioleaching was studied using Acidithiobacillus ferrooxidans. The results indicated that graphene and visible light could significantly accelerate chalcopyrite dissolution. The concentration of dissolved copper in the light system without graphene was $24.8 \%$ higher than the control group without light and graphene. The copper solubilization rate in the dark system with graphene was slightly higher than the control group. The copper solubilization rate of the group with light and $1.0 \mathrm{~g} \mathrm{~L}^{-1}$ graphene was the highest in comparison to others, and it was $50.3 \%$ higher than the control group. It was shown that the enhancing effect of the synergy catalysis was much more significant than when only using a single catalytic method. Bioleaching results, X-ray diffraction (XRD), cyclic voltammetry (CV), scanning electron microscopy (SEM) and elemental X-ray microanalysis (EDS) analysis indicated that the synergistic catalytic effect of graphene and light could primarily be attributed to the promotion of $\mathrm{Fe}^{3+} / \mathrm{Fe}^{2+}$ cycling and inhibition jarosites formation on the chalcopyrite surface.

Received 8th September 2017 Accepted 18th October 2017

DOI: 10.1039/c7ra10015a

rsc.li/rsc-advances methods such as adjustment of optimum redox potentials and $\mathrm{pH}$, using mixed thermophilic bacteria, and addition of activated carbon, silver ions and L-cysteine have been used for enhancing bioleaching. ${ }^{17-23}$ These researches have already achieved some progresses, and all the methods have been proved to speed up the dissolution of copper. However, these studies neglect the semiconductor property of chalcopyrite during the bioleaching processes. Photocatalysis with semiconductors has been extensively studied in the last few decades, such as degradation of organic pollutants, generation of hydrogen and reduction of $\mathrm{CO}_{2} \cdot{ }^{24-26}$ Some researches have found that visible light-excited photoelectrons from semiconductor minerals are able to reduce $\mathrm{Fe}^{3+}$ to $\mathrm{Fe}^{2+}$, which can be used as energy substrate for Acidithiobacillus ferrooxidans growth. ${ }^{27,28}$ Chalcopyrite bioleaching can be achieved through two modes: contact and non-contact leaching. ${ }^{29}$ In these two modes, ferrous ions are oxidized to ferric ions by Acidithiobacillus ferrooxidans, then ferric ions attack chalcopyrite to dissolve it. Thus, ferrous ions and reduced inorganic sulfur compounds are released from chalcopyrite. Ferrous ions are re-oxidized by Acidithiobacillus ferrooxidans, and reduced inorganic sulfur compounds are oxidized to sulfates to maintain the acidic environment of the leaching system. As a result, the chalcopyrite get dissolved. A recent study has showed that visible light can significantly accelerate the copper extraction with the help of the semiconductor property of chalcopyrite. ${ }^{30}$ Photoexcited electrons from the semiconductor chalcopyrite could facilitate the reduction of $\mathrm{Fe}^{3+}$ to $\mathrm{Fe}^{2+}$ as metabolic substrates for A. ferrooxidans, leading to better biomass, lower $\mathrm{pH}$ and redox, which was 
conducive to chalcopyrite bioleaching. However, the rapid recombination of photogenerated electrons and holes (approximately $10 \mathrm{~ns}$ ) in chalcopyrite particles will limit the efficiency of photocatalytic chalcopyrite bioleaching. ${ }^{31,32}$ Hence, improving the charge separation is the key issue to enhance photocatalytic chalcopyrite bioleaching.

Graphene, two-dimensional graphitic carbon material with honeycomb crystal structure and single atomic layer, has attracted the attention of many scientists due to its unique properties, such as good electrical conductivity, high chemical stability, larger specific surface area and good transparency. ${ }^{33}$ These outstanding advantages can help graphene enhance the photocatalytic efficiency of semiconductor catalyst through promoting photogenerated electrons transfer and suppressing photogenerated electrons and holes recombination. ${ }^{34,35}$ However, to the best of our knowledge, no studies have been reported to the influence of graphene and visible light on chalcopyrite bioleaching. Therefore, in this paper, the effect of graphene and visible light on chalcopyrite bioleaching by Acidithiobacillus ferrooxidans was investigated separately by means of XRD, SEM-EDS and cyclic voltammetry to further understand the roles of graphene and visible light in bioleaching.

\section{Material and methods}

\subsection{Strain and culture conditions}

A. ferrooxidans strain (ATCC23270) purchased from American type culture collection was used in this study. The medium $9 \mathrm{~K}$ constituted of $\left(\mathrm{NH}_{4}\right)_{2} \mathrm{SO}_{4} 3 \mathrm{~g} \mathrm{~L}^{-1}, \mathrm{KCl} 0.1 \mathrm{~g} \mathrm{~L}^{-1}, \mathrm{~K}_{2} \mathrm{HPO}_{4} \cdot 3 \mathrm{H}_{2} \mathrm{O}$ $0.5 \mathrm{~g} \mathrm{~L}^{-1}, \mathrm{MgSO}_{4} \cdot 7 \mathrm{H}_{2} \mathrm{O} 0.5 \mathrm{~g} \mathrm{~L}^{-1}, \mathrm{Ca}\left(\mathrm{NO}_{3}\right)_{2} 0.01 \mathrm{~g} \mathrm{~L}^{-1}$ was used to culture $A$. ferrooxidans, which was adjusted to $\mathrm{pH} 2.0$ with $\mathrm{H}_{2} \mathrm{SO}_{4}\left(0.01 \mathrm{~mol} \mathrm{~L}^{-1}\right) .20 \mathrm{~g} \mathrm{~L}^{-1}$ chalcopyrite was added as energy substance. A. ferrooxidans was previously adapted into an orbital shaker at $30^{\circ} \mathrm{C}$ and $170 \mathrm{rpm}$ with $20 \mathrm{~g} \mathrm{~L}^{-1}$ chalcopyrite sample. The growth of bacteria was quantified by blood corpuscle counting using an optical microscope at $40 \times$ amplification. Cells were harvested at the mid-exponential growth phase with cell concentration of higher than $1.0 \times 10^{7}$ cells per $\mathrm{mL}$. The culture was incipiently filtered by Whatman 42 filter paper to exclude suspended solids. The suspension containing cells were subsequently centrifuged (10 $000 \mathrm{rpm})$ for $20 \mathrm{~min}$ at $25{ }^{\circ} \mathrm{C}$. The pellets were washed with sulfuric acid $\left(0.01 \mathrm{~mol} \mathrm{~L}^{-1}\right)$ to obtain metabolites-free cells and then suspended in sterilized $9 \mathrm{~K}$ medium.

\subsection{Preparation of minerals sample}

The chalcopyrite sample used in the bioleaching experiments was obtained from Guangxi, China. The ground mineral was sieved to a particle diameter of $43-74 \mu \mathrm{m}$. The X-ray diffraction analysis showed that the mineral was consisted primarily of chalcopyrite, jarosite and sulfur (showed in Table 1).

\subsection{Bioleaching experiments}

All the bioleaching experiments were undertaken in a constant temperature illumination shaker (TS-2102GZ), where the temperature was set to $30{ }^{\circ} \mathrm{C}$ and the light intensity could be regulated. Parallel fluorescent light bulbs located at the top of flasks acted as the light source. Bioleaching experiments were carried out in $250 \mathrm{~mL}$ flasks containing $100 \mathrm{~mL}$ sterilized 9K medium, $2 \mathrm{~g}$ chalcopyrite and various contents of graphene $(0.00 \mathrm{~g}, 0.02 \mathrm{~g}, 0.05 \mathrm{~g}, 0.10 \mathrm{~g}$ and $0.15 \mathrm{~g})$. The initial $\mathrm{pH}$ and inoculum was 2.0 and $3.2 \times 10^{7}$ cells per $\mathrm{mL}$, respectively. The light intensity was set to 8500 lux and 0 lux. The flasks incubated at $30^{\circ} \mathrm{C}$ and $170 \mathrm{rpm}$ on illumination shaker for 36 days. During the bioleaching process, the $\mathrm{pH}$ and redox potentials were monitored regularly. A volume of $0.1 \mathrm{~mL}$ of solution samples were removed to evaluate the cupric ion, total iron, ferrous ion and bacterial concentrations. Sterilized distilled water was used to compensate for the water evaporation, and equal volumes of sterilized $9 \mathrm{~K}$ medium $(\mathrm{pH}=2)$ was added to compensate for the losses due to sampling for analyses. All the bioleaching experiments were carried out in duplicate to guarantee dependability.

\subsection{Electrochemical measurements}

The carbon paste electroactive electrode (CPEE) contained $0.7 \mathrm{~g}$ of minerals, $0.1 \mathrm{~g}$ of solid paraffin and $0.2 \mathrm{~g}$ of graphite was used as the working electrode. Electrochemical experiments were carried out by a conventional three-electrode system, which consisted of a working electrode, two wired graphite rods as the

Table 1 The analysis of ore residues and original chalcopyrite by XRD at the end of bioleaching

\begin{tabular}{|c|c|c|c|c|c|c|}
\hline \multirow[b]{2}{*}{ Different concentration } & \multirow[b]{2}{*}{ Different light condition } & \multirow[b]{2}{*}{ Time (day) } & \multicolumn{4}{|c|}{ The content of components in residues (\%) } \\
\hline & & & Chalcopyrite & Jarosite & Sulfur & Pyrite \\
\hline - & 8500 lux & 36 & 64.8 & 32.5 & 2.2 & 0.4 \\
\hline- & Dark & 36 & 76.9 & 19.7 & 3.1 & 0.3 \\
\hline $0.5 \mathrm{~g} \mathrm{~L}^{-1}$ graphene & 8500 lux & 36 & 64.7 & 31.5 & 3.5 & 0.3 \\
\hline $1.0 \mathrm{~g} \mathrm{~L}^{-1}$ graphene & Dark & 36 & 72.6 & 24.9 & 2.3 & 0.2 \\
\hline $1.5 \mathrm{~g} \mathrm{~L}^{-1}$ graphene & 8500 lux & 36 & 55.1 & 42.0 & 2.3 & 0.6 \\
\hline $1.5 \mathrm{~g} \mathrm{~L}^{-1}$ graphene & Dark & 36 & 68.1 & 29.1 & 2.3 & 0.5 \\
\hline
\end{tabular}


counter electrode and a $\mathrm{Ag} / \mathrm{AgCl}(3.0 \mathrm{M} \mathrm{KCl})$ electrode as the reference electrode. The working electrode surface was polished with 3000 silicon carbide papers, and then rinsed with deionized water before each electrochemical measurement. ${ }^{36}$ The electrolyte was $9 \mathrm{~K}$ medium (no ferrous sulfate) whose $\mathrm{pH}$ value was adjusted to 2.0 with diluted sulfuric acid $\left(0.01 \mathrm{~mol} \mathrm{~L}^{-1}\right)$. Before the start of all electrochemical tests, the ultra-pure nitrogen gas were bubbled into the electrolyte solution for at least $20 \mathrm{~min}$. The scan route started scanning initially from 0 to $800 \mathrm{mV}$, then reversed to $-800 \mathrm{mV}$ and finally switched back to $0 \mathrm{mV}$ again. All tests were carried out at a scan rate of $20 \mathrm{mV} \mathrm{s}^{-1}$ (vs. $\mathrm{Ag} / \mathrm{AgCl}$ ) in $\mathrm{N}_{2}$ atmosphere.

\subsection{Analytical techniques}

The concentration of copper ion and iron were determined by BCO spectrophotometry and $o$-phenanthroline spectrophotography, respectively (their correlation coefficient of standard curve- $r$ is greater or equal to 0.999$)$. The bacterial concentration was measured by optical microscope (CX31). A pH meter (PHS3C) and a Pt electrode using a $\mathrm{Ag} / \mathrm{AgCl}$ electrode $(3.0 \mathrm{M} \mathrm{KCl})$ as reference were employed to measure the $\mathrm{pH}$ values and redox potentials of the bioleaching solution. The surface features of mineral residues and mineral composition changes were examined by Scanning Electron Microscope (SEM), Energy Dispersion Spectrum (EDS) and X-ray diffraction (XRD)
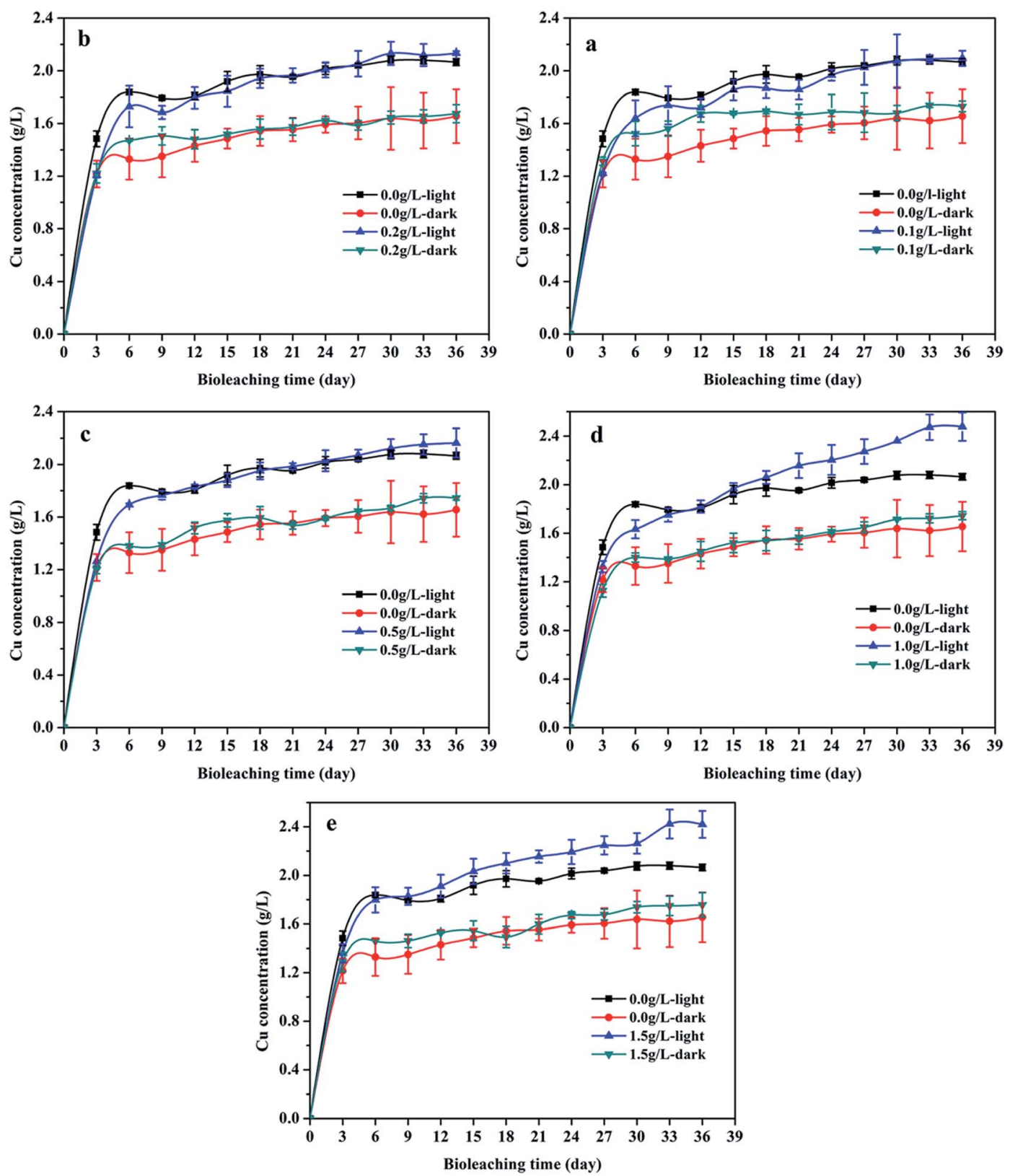

Fig. 1 Changes in concentration (mean \pm SD) of dissolved copper during chalcopyrite bioleaching at different concentration of graphene under light or dark condition (a, b, c, d and e): (a) the groups with $0.1 \mathrm{~g} \mathrm{~L}^{-1}$ graphene and control groups; (b) the groups with $0.2 \mathrm{~g} \mathrm{~L}{ }^{-1} \mathrm{graphene}$ and control groups; (c) the groups with $0.5 \mathrm{~g} \mathrm{~L}^{-1}$ graphene and control groups; (d) the groups with $1.0 \mathrm{~g} \mathrm{~L}^{-1}$ graphene and control groups; (e) the groups with $1.5 \mathrm{~g} \mathrm{~L}^{-1}$ graphene and control groups. 
analyses. Luminous intensity was determined with TES-1330A digital light meter.

\section{Results and discussion}

\subsection{Effect of graphene and visible light on chalcopyrite bioleaching}

The contribution of graphene and visible light to the bioleaching of chalcopyrite was investigated. As can be seen in Fig. 1, copper extraction increased quickly during the first 6 days, and then the rate of chalcopyrite dissolution became slow, which may be credited to the inhibition of passive film formation on copper extraction. The final copper extraction concentrations were $2.06 \pm 0.03 \mathrm{~g} \mathrm{~L}^{-1}, 2.09 \pm 0.06 \mathrm{~g} \mathrm{~L}^{-1}, 2.13 \pm$ $0.02 \mathrm{~g} \mathrm{~L}^{-1}, 2.16 \pm 0.11 \mathrm{~g} \mathrm{~L}^{-1}, 2.48 \pm 0.12 \mathrm{~g} \mathrm{~L}^{-1}, 2.42 \pm 0.11 \mathrm{~g} \mathrm{~L}^{-1}$ for the visible light irradiation in the presence of $0,0.1,0.2,0.5$, 1.0 and $1.5 \mathrm{~g} \mathrm{~L}^{-1}$ graphene, respectively. By comparison, the final copper extraction concentrations of the bioleaching systems without light irradiation in the presence of $0,0.1,0.2$, $0.5,1.0$ and $1.5 \mathrm{~g} \mathrm{~L}^{-1}$ graphene were $1.65 \pm 0.20 \mathrm{~g} \mathrm{~L}^{-1}, 1.73 \pm$ $0.04 \mathrm{~g} \mathrm{~L}^{-1}, 1.68 \pm 0.07 \mathrm{~g} \mathrm{~L}^{-1}, 1.74 \pm 0.02 \mathrm{~g} \mathrm{~L}^{-1}, 1.74 \pm 0.03 \mathrm{~g} \mathrm{~L}^{-1}$, $1.76 \pm 0.10 \mathrm{~g} \mathrm{~L}^{-1}$, respectively. The results indicated that visible light and graphene accelerated the copper leaching significantly. The dissolved copper in the light system without graphene was $24.8 \%$ higher than that in the control without light and graphene. The copper solubilization rate in the dark system


Fig. 2 Iron concentration (mean \pm SD) during chalcopyrite bioleaching at different concentration of graphene under light or dark condition (a, b, $c, d$ and e): (a) the groups with $0.1 \mathrm{~g} \mathrm{~L}^{-1}$ graphene and control groups; (b) the groups with $0.2 \mathrm{~g} \mathrm{~L}^{-1}$ graphene and control groups; (c) the groups with $0.5 \mathrm{~g} \mathrm{~L}^{-1}$ graphene and control groups; (d) the groups with $1.0 \mathrm{~g} \mathrm{~L}^{-1}$ graphene and control groups; (e) the groups with $1.5 \mathrm{~g} \mathrm{~L}^{-1} \mathrm{graphene}$ and control groups. 
with graphene was slightly higher than the control group. The copper solubilization rate of group with visible light and $1.0 \mathrm{~g}$ $\mathrm{L}^{-1}$ graphene was the highest in comparison to others, and it was $50.3 \%$ higher than that of the control group. It was shown that the enhancing effect of the synergy catalysis was much more significant than that when only using a single catalytic method.

Fig. 2 showed that the variation trend of the concentration of total iron and ferrous iron in each group were essentially similar. The total iron concentration increased at first, then decreased owing to the precipitation of the soluble ferric iron $\left(\mathrm{Fe}^{3+}\right)$ as jarosite (eqn (5)). The total iron concentration of the light group was higher than that of the unilluminated group, and a higher graphene concentration resulted in more dissolved iron. The main biochemical reactions during the bioleaching are listed as eqn (1)-(5). ${ }^{37}$ The presence of $\mathrm{Fe}^{3+}$ in the leaching medium has been widely accepted as the primary factor for the indirect leaching mechanism of chalcopyrite (eqn (1)), ${ }^{38}$ and ferrous iron $\left(\mathrm{Fe}^{2+}\right)$ can provide energy to A. ferrooxidans. Hence, the concentration of total iron was an important parameter in bioleaching of chalcopyrite. As can be seen from Fig. 1 and 2, high concentration of total iron would be beneficial to copper extraction. In contrast, ferrous iron concentration decreased quickly during the first 6 days, and then maintained at a lower level. It is probable owing to that rapid growth of bacteria consumed a large amount of ferrous ions. Compared to the unilluminated group, the ferrous iron concentration of the light group was marginally superior in the bioleaching system. In addition, it's worth noting that the ferrous iron concentration of the experimental groups with graphene and visible light were also slightly higher than that of the group without graphene under visible light condition. As illustrated in Fig. 3, the photocatalytic reactions took place on the surface of chalcopyrite and graphene. These reactions were activated by the application of light with energy equal to or greater than the band-gap energy, ${ }^{39}$ thereby exciting to generate electrons in the conduction band (CB) and holes in the valence band (VB) of chalcopyrite. Then, the excited electrons in the $\mathrm{CB}$ of

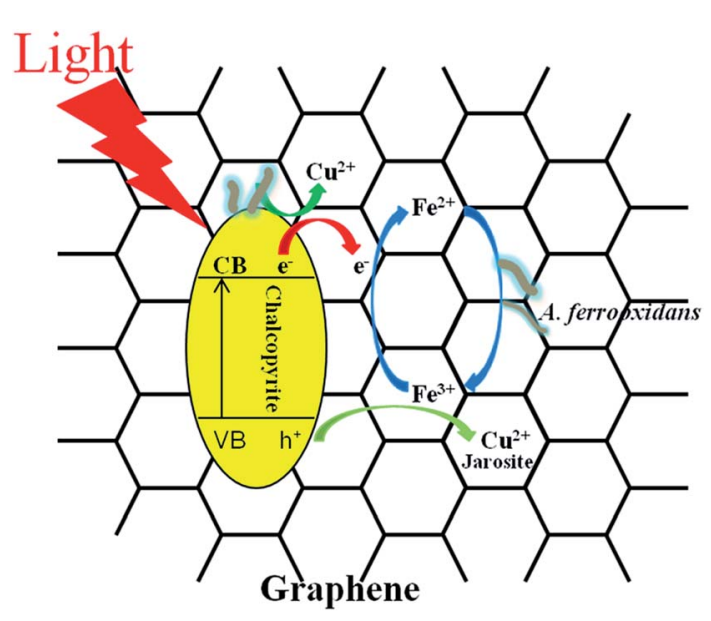

Fig. 3 The possible mechanism of enhancing chalcopyrite bioleaching through the synergistic effect of graphene and visible light. chalcopyrite could be easily transferred to the graphene due to its high electrical conductivity, thus suppressing the recombination of photogenerated electrons and holes in chalcopyrite. The high separation rate of electron-hole pairs made photogenerated electrons easier to reduce $\mathrm{Fe}^{3+}$ to $\mathrm{Fe}^{2+}$, giving rise to the regeneration of $\mathrm{Fe}^{2+}$ in the photocatalytic system. Hence, compared to the control samples under visible light condition without graphene, the regeneration of $\mathrm{Fe}^{2+}$ was superior in the bioleaching system with visible light and graphene. The regeneration of $\mathrm{Fe}^{2+}$, which acted as a metabolical substrate for A. ferrooxidans, appeared in the light-induced system. This was consistent with the results shown in Fig. 4. The growth of $A$. ferrooxidans during the visible light treatment was accelerated. It was apparent that free cell density in visible light treatment was larger than that subjected to dark condition. The free cell density of groups containing graphene was less than that of the group without graphene except that the free cell density of the group with $0.1 \mathrm{~g} \mathrm{~L}^{-1}$ graphene was marginally higher than the group without graphene when illuminated with visible light. What's more, the free cell density decreased with increasing graphene concentration. These phenomenas maybe due to graphene has a large specific area, which can absorb a large number of free cells to make a lot of free cells decreasing. Hence, graphene might be able to reduce attached cells on the chalcopyrite surface to reduce the formation of passivation and enhance the bioleaching of chalcopyrite. ${ }^{37}$

$$
\begin{gathered}
\mathrm{CuFeS}_{2}+4 \mathrm{Fe}^{3+} \rightarrow \mathrm{Cu}^{2+}+5 \mathrm{Fe}^{2+}+2 \mathrm{~S}^{0} \\
\mathrm{CuFeS}_{2}+4 \mathrm{H}^{+}+\mathrm{O}_{2} \rightarrow \mathrm{Cu}^{2+}+\mathrm{Fe}^{2+}+2 \mathrm{~S}^{0}+2 \mathrm{H}_{2} \mathrm{O} \\
4 \mathrm{Fe}^{2+}+4 \mathrm{H}^{+}+\mathrm{O}_{2} \stackrel{A \cdot f}{\longrightarrow} 4 \mathrm{Fe}^{3+}+2 \mathrm{H}_{2} \mathrm{O} \\
2 \mathrm{~S}^{0}+3 \mathrm{O}_{2}+2 \mathrm{H}_{2} \mathrm{O} \stackrel{A \cdot f}{\longrightarrow} 2 \mathrm{SO}_{4}^{2-}+4 \mathrm{H}^{+} \\
\mathrm{K}^{+}+3 \mathrm{Fe}^{3+}+2 \mathrm{SO}_{4}^{2-}+6 \mathrm{H}_{2} \mathrm{O} \rightarrow \mathrm{KFe}_{3}\left(\mathrm{SO}_{4}\right)_{2}(\mathrm{HO})_{6}+6 \mathrm{H}^{+}
\end{gathered}
$$

Fig. 5 showed the $\mathrm{pH}$ value of solution during chalcopyrite bioleaching. The $\mathrm{pH}$ value of the bioleaching system increased in the first 3 days and subsequently decreased to below 1.9. The $\mathrm{pH}$ value of the bioleaching system under visible light illumination was lower than that of the dark treatment. In addition, the $\mathrm{pH}$ value of leaching solution increased with increasing graphene concentration, and it maybe due to graphene could adsorb hydrogen ions and cushion $\mathrm{pH}$. The initial increase of $\mathrm{pH}$ can be attributed to the consumption of hydrogen ions as there were no available oxidizing agents in the leaching system (eqn (2) and (3)). The following drop in $\mathrm{pH}$ implies the generation of acids, which were produced by $A$. ferrooxidans oxidizing elemental sulfur to sulfuric acid as well as the result of jarosite precipitation (eqn (4) and (5)). In comparison to the dark system, the more prominent $\mathrm{pH}$ decrease of the visible light illumination system was a result of more acid generated by higher biomass production and more Fe(III) precipitation, which was reflected in the experiments results (showed in Fig. 4 and Table 1). Therefore, it was able to determine that 

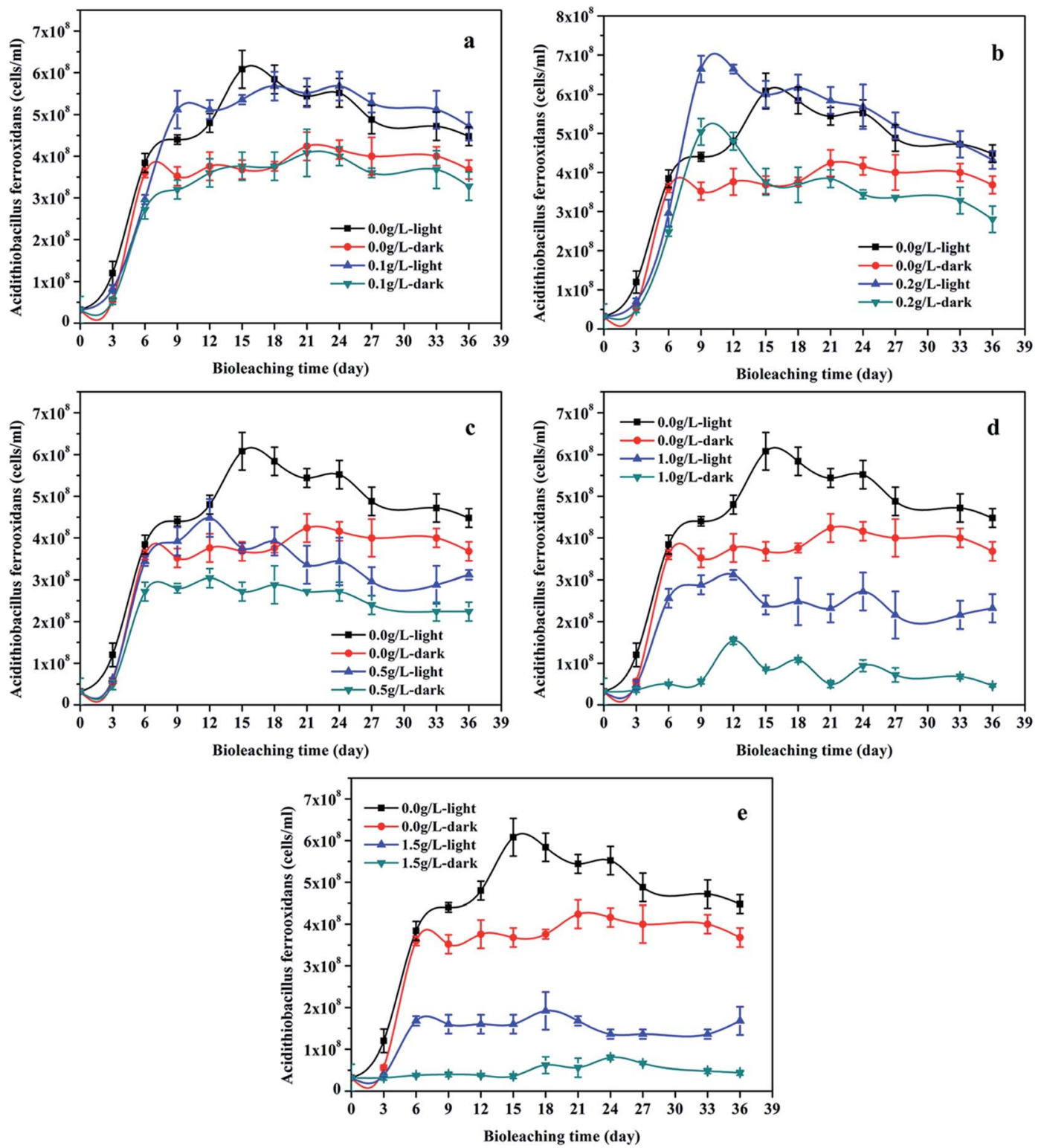

Fig. 4 Cells concentration (mean \pm SD) during chalcopyrite bioleaching at different concentration of graphene under light or dark condition (a, b, c, d and e): (a) the groups with $0.1 \mathrm{~g} \mathrm{~L}^{-1}$ graphene and control groups; (b) the groups with $0.2 \mathrm{~g} \mathrm{~L}^{-1}$ graphene and control groups; (c) the groups with $0.5 \mathrm{~g} \mathrm{~L}^{-1}$ graphene and control groups; (d) the groups with $1.0 \mathrm{~g} \mathrm{~L}^{-1}$ graphene and control groups; (e) the groups with $1.5 \mathrm{~g} \mathrm{~L}^{-1} \mathrm{graphene}$ and control groups.

illumination was favorable to acid formation, which promoted the bioleaching process of chalcopyrite.

The influence of visible light and graphene concentration on redox potential was showed in Fig. 5. It was observed that the oxidation-reduction potential of the chalcopyrite bioleaching system quickly increased to more than $540 \mathrm{mV}$ in the first six days, and then remained in a relatively stable range. Compared with the unilluminated group, the light group had a lower oxidation-reduction potential, while the graphene added system had a higher oxidation-reduction potential than the group without graphene. The redox potential was partially correlated to the proportion of $\mathrm{Fe}^{3+} / \mathrm{Fe}^{2+}$ species. The lower potential, which appeared in the lighted bioleaching system, was a result of regeneration of $\mathrm{Fe}^{2+}$ and continuous cycling of $\mathrm{Fe}^{3+} / \mathrm{Fe}^{2+}$, which was further induced by semiconducting mineral photocatalysis. The chalcopyrite bioleaching system containing graphene had a higher potential due to it had a higher concentration of ferric ion (as shown in Fig. 2). All in all, visible light and graphene can augment copper bioleaching by accelerating the circulation of ferric ion and ferrous ion of bioleaching system.

\subsection{SEM-EDS analysis}

The surface morphologies of the chalcopyrite residues during bioleaching were observed by SEM (Fig. 6). The SEM image of the original graphene surface was shown in Fig. 6a, and the 

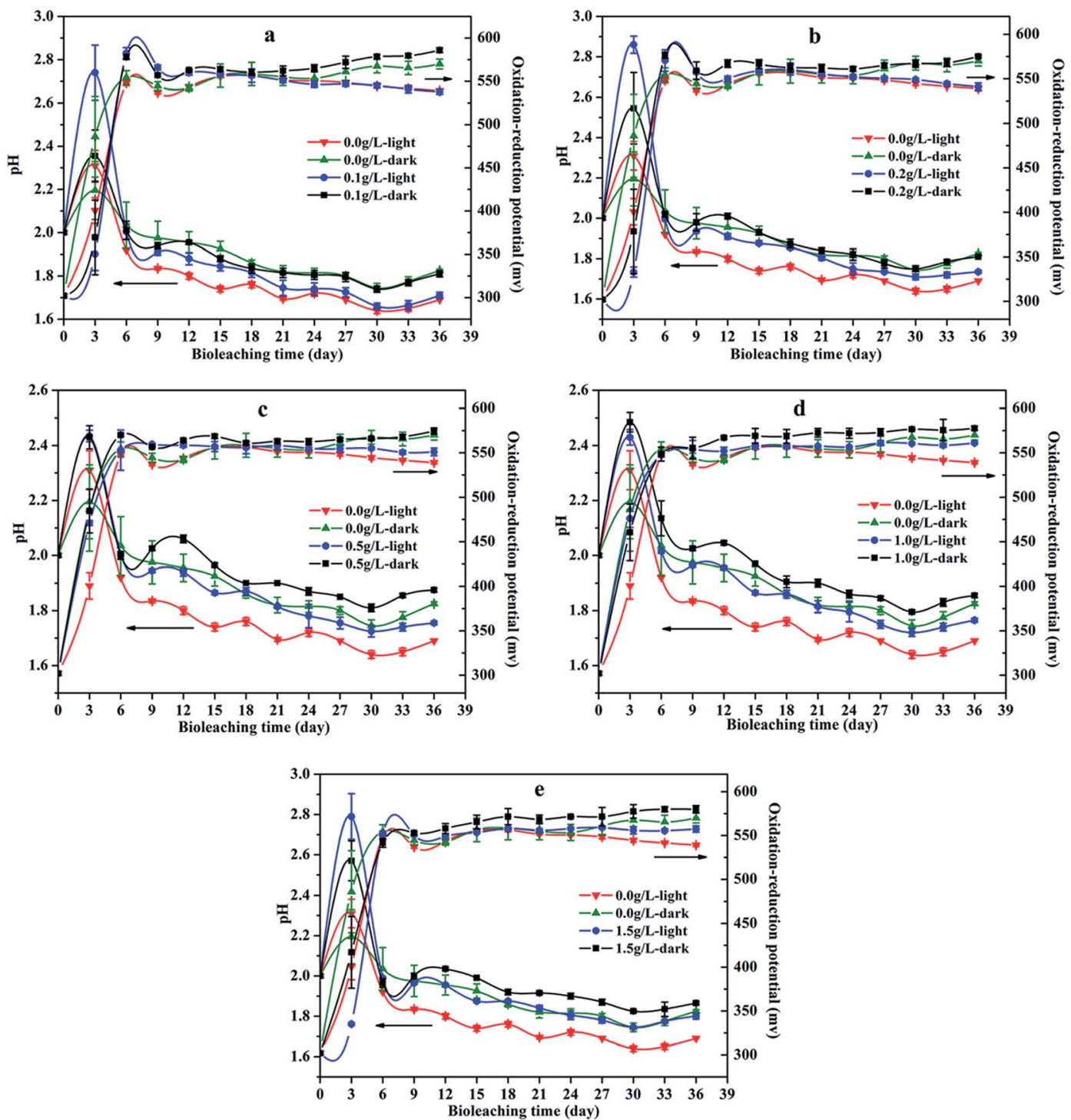

Fig. $5 \mathrm{pH}$ (mean \pm SD) and redox potential (mean \pm SD) during chalcopyrite bioleaching at different concentration of graphene under light or dark condition ( $a, b, c, d$ and e): (a) the groups with $0.1 \mathrm{~g} \mathrm{~L}^{-1}$ graphene and control groups; (b) the groups with $0.2 \mathrm{~g} \mathrm{~L}^{-1}$ graphene and control groups; (c) the groups with $0.5 \mathrm{~g} \mathrm{~L}^{-1}$ graphene and control groups; (d) the groups with $1.0 \mathrm{~g} \mathrm{~L}^{-1}$ graphene and control groups; (e) the groups with $1.5 \mathrm{~g} \mathrm{~L}^{-1}$ graphene and control groups.

surface was smooth and clear. The surface morphology of the original chalcopyrite was shown in Fig. 6b, demonstrating that there was no jarosites attached to the surface. These images revealed that graphene surface of residues containing $1.5 \mathrm{~g} \mathrm{~L}^{-1}$ graphene were covered with a large number of jarosites (micro particles) (Fig. 6c and d). Jarosites were some cubic crystals, and their size was between $200 \mathrm{~nm}$ and $1000 \mathrm{~nm} .{ }^{40}$ Only a small amount of jarosite particles attached on the chalcopyrite surface of residues containing $1.5 \mathrm{~g} \mathrm{~L}^{-1}$ graphene (Fig. 6e and f). However, the chalcopyrite surface of residues without graphene contained a large number of jarosites (Fig. $6 \mathrm{~g}$ and $\mathrm{h}$ ). The results showed that graphene could facilitate jarosites formation on the surface of graphene. Therefore, it could suppress jarosites formation on the surface of chalcopyrite and enhance the bioleaching of chalcopyrite.
Table 2 listed the results of EDS. The mass fractions of elements in original chalcopyrite for $\mathrm{C}, \mathrm{O}, \mathrm{Cu}, \mathrm{Fe}$ and $\mathrm{S}$ were $0.00 \%, 5.23 \%, 32.62 \%, 29.82 \%, 28.52 \%$, respectively. In residue leached under light condition in the absence of graphene, the mass fractions of elements for $\mathrm{C}, \mathrm{O}, \mathrm{Cu}, \mathrm{Fe}$ and $\mathrm{S}$ were $0.00 \%$, $16.77 \%, 13.28 \%, 35.19 \%, 31.23 \%$, respectively, and the mass fractions of elements for $\mathrm{C}, \mathrm{O}, \mathrm{Cu}, \mathrm{Fe}$ and $\mathrm{S}$ in the residue without visible light and graphene were $0.00 \%, 15.24 \%, 17.69 \%$, $34.93 \%, 28.58 \%$, respectively. In residue with light and $1.0 \mathrm{~g} \mathrm{~L}^{-1}$ graphene, the mass fractions of elements for $\mathrm{C}, \mathrm{O}, \mathrm{Cu}, \mathrm{Fe}$ and $\mathrm{S}$ were $21.27 \%, 18.40 \%, 18.31 \%, 20.13 \%, 19.10 \%$, respectively, and the mass fractions of elements for $\mathrm{C}, \mathrm{O}, \mathrm{Cu}, \mathrm{Fe}$ and $\mathrm{S}$ in the residue under dark condition in the presence of $1.0 \mathrm{~g} \mathrm{~L}^{-1}$ graphene were $22.25 \%, 17.89 \%, 18.71 \%, 19.47 \%, 18.58 \%$, respectively. The results indicated that the surface copper was 

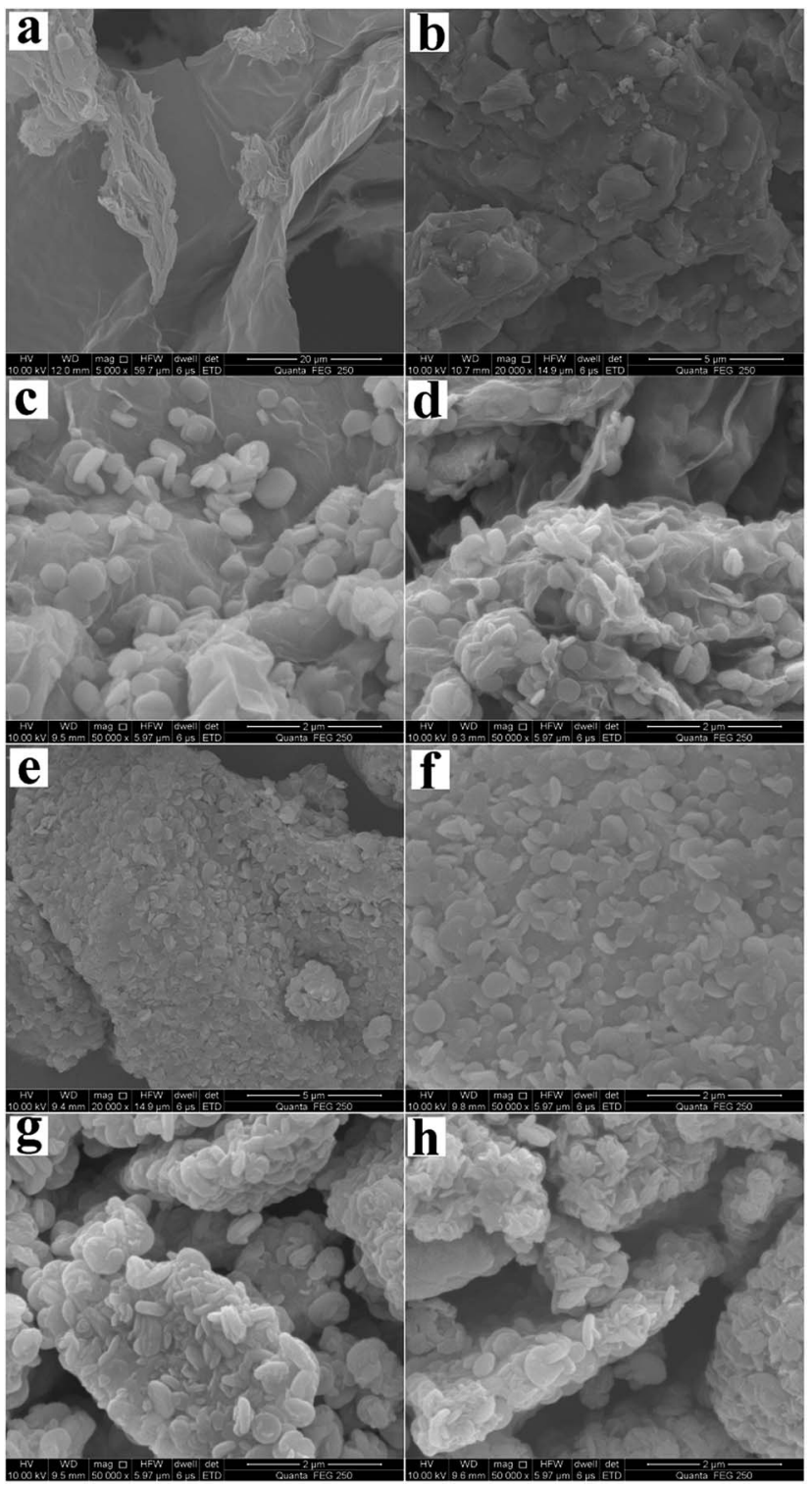

Fig. 6 SEM images of graphene and chalcopyrite surface: (a) original graphene surface; (b) original chalcopyrite surface; (c) and (d) graphene surface of the residues containing $1.5 \mathrm{~g} \mathrm{~L}^{-1}$ graphene under light and dark condition, respectively; (e) and (f) chalcopyrite surface morphology for the residues containing $1.5 \mathrm{~g} \mathrm{~L}^{-1}$ graphene under light and dark condition, respectively; (g) and (h) chalcopyrite surface of the residues without graphene under light and dark condition, respectively. relatively reduced after bioleaching due to copper was dissolved, and the surface copper of residue under light condition without graphene was lower than the dark system without graphene owing to the light system had more copper dissolved out during the bioleaching. By contrast, the surface sulphur, oxygen and iron element were relatively rich after bioleaching of chalcopyrite because of the formation of sulfurs and jarosites. In addition, the surface of residues with graphene contained higher levels of $\mathrm{C}$ element and lower $\mathrm{Fe}, \mathrm{S}$ element. The results indicated that the graphene can cover on the surface of the chalcopyrite and reduce jarosite formation on the chalcopyrite surface to increase the chalcopyrite bioleaching. These results were consistent with the bioleaching experiments and XRD results.

\subsection{XRD analysis of chalcopyrite}

The XRD phase retrieval analysis showed that the main composition of the leached residues was chalcopyrite, jarosite, sulfur and pyrite (Fig. 7). The residues of light group contained more jarosites and much less chalcopyrite than the controls without light. As graphene concentration increased, jarosites of residue increased, while the content of chalcopyrite decreased. The residues contained small amounts of sulfur, and the content of sulfur in each group is almost the same. We speculate that it may be due to most of the sulfur element would be oxidized by Acidithiobacillus ferrooxidans to higher valence sulfur oxides in the bioleaching process (eqn (4)). ${ }^{37}$ It was confirmed that jarosite was the most abundant product that will be continuously accumulated during the bioleaching of chalcopyrite. ${ }^{41}$ Jarosite precipitation was the key factors for chalcopyrite passivation. Visible light could enhance chalcopyrite bioleaching, and it would also lead to more jarosite production and inhibit the further dissolution of chalcopyrite. Graphene could facilitate a large number of jarosites formation on its surface and reduce jarosites formation on the surface of chalcopyrite. Hence, graphene could further enhance the bioleaching of chalcopyrite. It was also well illustrated by the results of copper extraction. The leaching rate of the light system with graphene was faster than that of the light system without graphene in the later stage (Fig. 1).

\subsection{Cyclic voltammetry analysis}

The cyclic voltammograms of original chalcopyrite electrode and chalcopyrite residue electrodes in $9 \mathrm{~K}$ medium were shown

Table 2 The analysis of ore residues and original chalcopyrite by EDS at the end of bioleaching

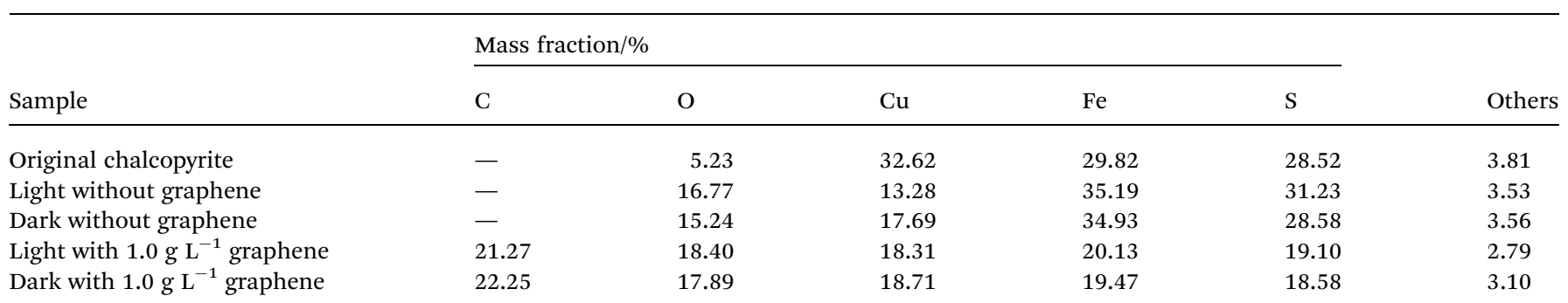




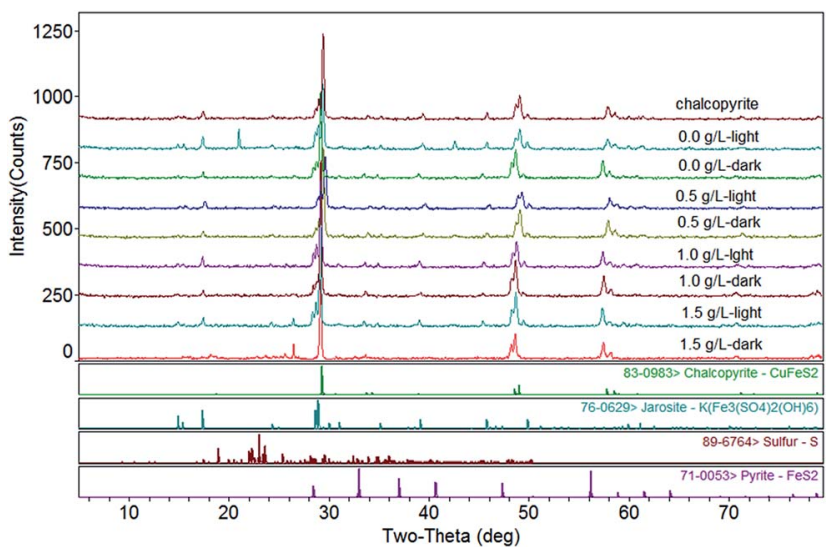

Fig. 7 XRD patterns of original chalcopyrite and chalcopyrite residues after bioleaching at different concentration of graphene under light or dark condition.

in Fig. 8. Two cathodic peaks ( $\mathrm{C} 1$ and $\mathrm{C} 2)$ and three anodic peaks (A1, A3 and A4) were detected at original chalcopyrite electrode, while two cathodic peaks (C1 and C2) and four anodic peaks (A1, A2, A3 and A4) were detected at electrodes of chalcopyrite residues without graphene (Fig. 8a). According to many other studies, the anodic and cathodic peaks can be assigned to the corresponding oxidation-reduction reactions. ${ }^{42-44}$ The peaks A1 and A2 should represent the formation and further oxidation of chalcocite $\left(\mathrm{Cu}_{2} \mathrm{~S}\right)$, and peak $\mathrm{A} 3$ might represent the oxidation of hydrogen sulfide to elemental sulfur as reported by many researchers (eqn (6)-(8)). ${ }^{36,45-47}$ Peak A4 could be seen a pre-wave, it represented the decomposition of chalcopyrite to intermediate species as shown in eqn (9). ${ }^{42,46}$

$$
\begin{gathered}
\mathrm{Cu}_{2} \mathrm{~S} \rightarrow \mathrm{Cu}_{2-x} \mathrm{~S}+x \mathrm{Cu}^{2+}+2 x \mathrm{e}^{-} \\
\mathrm{Cu}_{2-x} \mathrm{~S} \rightarrow \mathrm{CuS}+(1-x) \mathrm{Cu}^{2+}+2(1-x) \mathrm{e}^{-} \\
\mathrm{H}_{2} \mathrm{~S} \rightarrow \mathrm{S}^{0}+2 \mathrm{H}^{+}+2 \mathrm{e}^{-} \\
\mathrm{CuFeS}_{2} \rightarrow \mathrm{Cu}_{1-x} \mathrm{Fe}_{1-y} \mathrm{~S}_{2-z}+x \mathrm{Cu}^{2+}+y \mathrm{Fe}^{2+} \\
+\mathrm{S}^{0}+2(x+y) \mathrm{e}^{-}
\end{gathered}
$$

Peak C1 could represent the reduction of ferric ions, copper ions and elemental sulfur shown as eqn (10)-(12), and peak C2 could be associated with reduction of covellite to chalcocite shown as eqn (13)..$^{4-49}$

$$
\begin{gathered}
\mathrm{Fe}^{3+}+\mathrm{e}^{-} \rightarrow \mathrm{Fe}^{2+} \\
\mathrm{Cu}^{2+}+\mathrm{S}^{0}+2 \mathrm{e}^{-} \rightarrow \mathrm{CuS} \\
\mathrm{Cu}^{2+}+2 \mathrm{e}^{-} \rightarrow \mathrm{Cu}^{0} \\
\mathrm{Cu}_{2} \mathrm{~S}+\mathrm{H}^{+}+2 \mathrm{e}^{-} \rightarrow 2 \mathrm{Cu}^{0}+\mathrm{HS}^{-}
\end{gathered}
$$
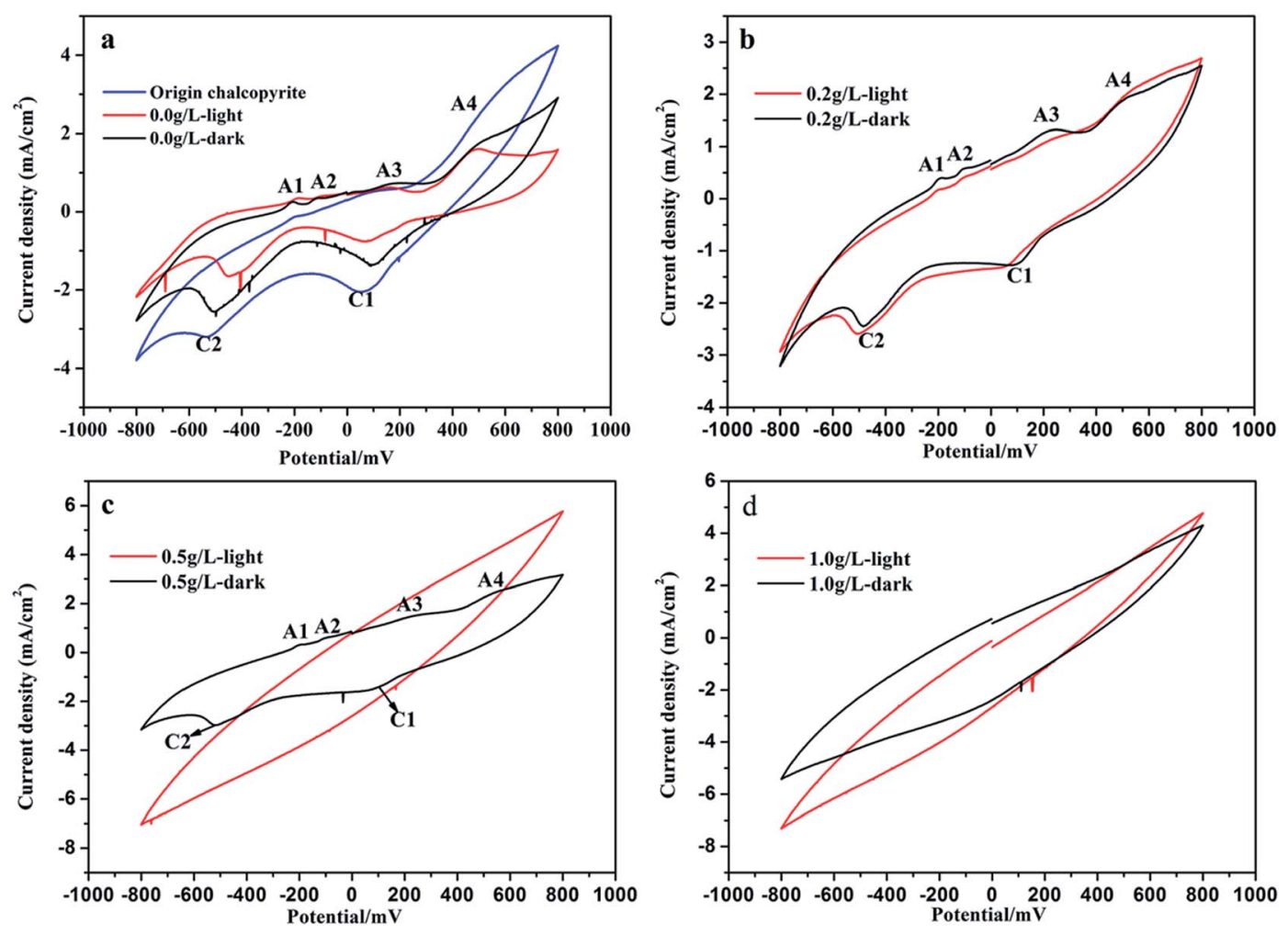

Fig. 8 Cyclic voltammograms of origin chalcopyrite electrode and electrodes of ore residues after bioleaching at different concentration of graphene under light or dark condition ( $a, b, c$ and d): (a) original chalcopyrite and the residues without graphene under light and dark condition; (b) the residues with $0.2 \mathrm{~g} \mathrm{~L}^{-1}$ graphene under light and dark condition; (c) the residues with $0.5 \mathrm{~g} \mathrm{~L}^{-1}$ graphene under light and dark condition; (d) the residues with $1.0 \mathrm{~g} \mathrm{~L}^{-1}$ graphene under light and dark condition. 
The cyclic voltammogram curves of the three electrodes of origin chalcopyrite and residues without graphene were similar, while the current densities were significantly different. The anodic current density of peak A4 and the cathodic current density of peaks C1 and C2 of the electrode of residue under light condition without graphene were not only lower than origin chalcopyrite electrode, but also lower than electrode of residue under dark condition without graphene (Fig. 8a). It was shown that the chalcopyrite residue under light condition without graphene had a lower oxidation-reduction rate than the dark group without graphene. This could mainly be attributed to chalcopyrite dissolution and passivation formation during the bioleaching, and the light group had more chalcopyrite dissolution and passivation formation than the dark group during the bioleaching. These were in accord with the results of bioleaching and XRD analysis. The leaching rate of the light group without graphene was $24.8 \%$ higher than the dark group without graphene. There were higher jarosite formation on the light group without graphene than that on the dark group without graphene (showed Table 1 and Fig. 1). The addition of the graphene group has a weaker redox peak compared to the control group, and the redox peak of the electrode became more obscure with the increasing of the content of graphene. Furthermore, the redox peaks of electrodes of ore residues under dark condition were more obvious than the light group (Fig. 8b-d). When the concentration of graphene reached $1 \mathrm{~g}$ $\mathrm{L}^{-1}$, the cyclic voltammetry curves of electrodes had no redox peak (Fig. 8d). These maybe due to chalcopyrite was wrapped by graphene that has the characteristics of double layer capacitance, and light group or graphene addition group had more chalcopyrite dissolution and passivation formation. These were well consistent with the results of bioleaching, XRD analysis and SEM observation. The light group and the graphene group had a higher leaching rate compared with the control group without light and graphene (showed in Fig. 1). The results of cyclic voltammetry analysis and leaching results showed that both light and graphene could promote the dissolution of chalcopyrite. The results of XRD analysis showed that the residues of the light group and the graphene group contained more jarosites (showed in Fig. 7 and Table 1). This indicated that the formation of excessive jarosites on the light group would further inhibit the photocatalytic efficiency. SEM observation results showed that residues surface of graphene group was covered by a large amount of graphene, and graphene surface of residues contained a large amount of jarosites (showed in Fig. 6c and d). This shows that graphene could facilitate jarosites formation on the surface of graphene to suppress jarosites formation on the surface of chalcopyrite and enhance the bioleaching. The results indicated that visible light and graphene could promote chalcopyrite bioleaching.

\section{Conclusions}

Graphene and visible light could accelerate copper bioleaching by $A$. ferrooxidans. Furthermore, the enhancing effect of the synergy catalysis was much more significant than that when only using a single catalytic method. The copper solubilization rate of group with visible light and $1.0 \mathrm{~g} \mathrm{~L}^{-1}$ graphene was the highest in comparison to others, and it was 50.3\% higher than that of the control group. Graphene and visible light could significantly accelerate the $\mathrm{Fe}^{3+} / \mathrm{Fe}^{2+}$ cycling, thus fostering copper bioleaching. In addition, graphene could facilitate jarosite formation on its surface to reduce jarosite formation on chalcopyrite surface, and therefore enhanced chalcopyrite bioleaching.

\section{Conflicts of interest}

There are no conflicts to declare.

\section{Acknowledgements}

This research was supported by the National Natural Science Foundation of China (41773089), the Fundamental Research Funds for the Central Universities of Central South University (2016zzts467) and the Open-End Fund for the Valuable and Precision Instruments of Central South University (CSUZC201608).

\section{References}

1 J. Zhu, Q. Wang, S. Zhou, Q. Li, M. Gan, H. Jiang, W. Qin, X. Liu, Y. Hu and G. Qiu, Colloids Surf., B, 2015, 126, 351-357.

2 Y. Yang, S. Harmer and M. Chen, Miner. Eng., 2014, 69, 185195.

3 Y. Yang, W. Liu and M. Chen, Miner. Eng., 2015, 70, 99-108. 4 S. Feng, H. Yang and W. Wang, RSC Adv., 2015, 5, 9805798066.

5 E. M. Córdoba, J. A. Muñoz, M. L. Blázquez, F. González and A. Ballester, Hydrometallurgy, 2008, 93, 81-87.

6 M. Dimitrijević, A. Kostov, V. Tasić and N. Milosević, J. Hazard. Mater., 2009, 164, 892-899.

7 M. Chen, L. Wu, X. Yi, K. Yang and H. Xie, Anal. Methods, 2017, 9, 3061-3066.

8 M. Gan, S. Zhou, M. Li, J. Zhu, X. Liu and L. Chai, Environ. Sci. Pollut. Res., 2015, 22, 5807-5816.

9 M. Gan, S. Jie, M. Li, J. Zhu and X. Liu, Mar. Pollut. Bull., 2015, 97, 47-55.

10 M. Zhang, B. Chen, N. Wang, J. Chen, L. Zou, X. Liu, Z. Wang, J. Wen and W. Liu, Int. Biodeterior. Biodegrad., 2016, DOI: 10.1016/j.ibiod.2016.05.023.

11 Y. Zhu, G. Zeng, P. Zhang, C. Zhang, M. Ren, J. Zhang and M. Chen, Bioresour. Technol., 2013, 142, 530-534.

12 P. Zhang, Y. Zhu, G. Zhang, S. Zou, G. Zeng and Z. Wu, Bioresour. Technol., 2009, 100, 1394-1398.

13 S. Feng, H. Yang and W. Wang, Bioresour. Technol., 2015, 192, 75-82.

14 J. Wang, X. Gan, H. Zhao, M. Hu, K. Li, W. Qin and G. Qiu, Miner. Eng., 2016, 98, 264-278.

15 D. Zhou, T. Peng, H. Zhou, X. Liu, G. Gu, M. Chen, G. Qiu and W. Zeng, Curr. Microbiol., 2015, 71, 62-69.

16 L. Ma, X. Wang, X. Feng, Y. Liang, Y. Xiao, X. Hao, H. Yin, H. Liu and X. Liu, Bioresour. Technol., 2017, 223, 121. 
17 C. Davis-Belmar, I. Gallardo, C. Demergasso and G. Rautenbach, Hydrometallurgy, 2012, 129, 135-139.

18 H. Zhao, J. Wang, C. Yang, M. Hu, X. Gan, L. Tao, W. Qin and G. Qiu, Hydrometallurgy, 2015, 151, 141-150.

19 Y. Wang, L. Su, L. Zhang, W. Zeng, J. Wu, L. Wan, G. Qiu, X. Chen and H. Zhou, Bioresour. Technol., 2012, 121, 348354.

20 C.-L. Liang, J.-L. Xia, X.-J. Zhao, Y. Yang, S.-Q. Gong, Z.-Y. Nie, C.-Y. Ma, L. Zheng, Y.-D. Zhao and G.-Z. Qiu, Hydrometallurgy, 2010, 105, 179-185.

21 S.-Y. Chen and J.-G. Lin, J. Hazard. Mater., 2009, 161, 893899.

22 Z. He, F. Gao, H. Zhong and Y. Hu, Bioresour. Technol., 2009, 100, 1383-1387.

23 X. Liu, B. Wu, B. Chen, J. Wen, R. Ruan, G. Yao and D. Wang, Hydrometallurgy, 2010, 103, 1-6.

24 H. Adamu, P. Dubey and J. A. Anderson, Chem. Eng. J., 2016, 284, 380-388.

25 N. Skillen, M. Adams, C. Mccullagh, Y. R. Su, F. Fina, M. R. Hoffmann, J. T. S. Irvine and P. K. J. Robertson, Chem. Eng. J., 2016, 286, 610-621.

26 O. Ola and M. M. Maroto-Valer, Chem. Eng. J., 2016, 283, 1244-1253.

27 A. Lu, Y. Li, S. Jin, X. Wang, X.-L. Wu, C. Zeng, H. Ding, R. Hao, M. Lv and C. Wang, Nat. Commun., 2012, 3, 768.

28 A. Lu, Y. Li and S. Jin, Elements, 2012, 8, 125-130.

29 F. K. Crundwell, Hydrometallurgy, 2003, 71, 75-81.

30 S. Zhou, M. Gan, J. Zhu, Q. Li, S. Jie, B. Yang and X. Liu, Bioresour. Technol., 2015, 182, 345-352.

31 S. Bassaid, D. Robert and M. Chaib, Appl. Catal., B, 2009, 86, 93-97.

32 Y. Cui, H. Du and L. Wen, Environ. Chem. Lett., 2009, 7, 321324.
33 L. Zhang, J. Zhang, H. Jiu, C. Ni, X. Zhang and M. Xu, J. Phys. Chem. Solids, 2015, 86, 82-89.

34 S. Song, B. Cheng, N. Wu, A. Meng, S. Cao and J. Yu, Appl. Catal., B, 2016, 181, 71-78.

35 J. Xu, L. Wang and X. Cao, Chem. Eng. J., 2016, 283, 816-825. 36 H. Zhao, J. Wang, X. Gan, X. Zheng, L. Tao, M. Hu, Y. Li, W. Qin and G. Qiu, Bioresour. Technol., 2015, 194, 28-35.

37 S. Feng, H. Yang and W. Wang, Bioresour. Technol., 2016, 200, 186-193.

38 Y. Yang, W. Liu and M. Chen, Miner. Eng., 2015, 70, 99-108.

39 M. Barakat, H. Schaeffer, G. Hayes and S. Ismat-Shah, Appl. Catal., B, 2005, 57, 23-30.

40 R. Yu, L. Shi, G. Gu, D. Zhou, L. You, M. Chen, G. Qiu and W. Zeng, Bioresour. Technol., 2014, 162, 300-307.

41 N. Pradhan, K. Nathsarma, K. S. Rao, L. Sukla and B. Mishra, Miner. Eng., 2008, 21, 355-365.

42 G. Gu, K. Hu, X. Zhang, X. Xiong and H. Yang, Electrochim. Acta, 2013, 103, 50-57.

43 C.-L. Liang, J.-L. Xia, Y. Yang, Z.-Y. Nie, X.-J. Zhao, L. Zheng, C.-Y. Ma and Y.-D. Zhao, Hydrometallurgy, 2011, 107, 13-21. 44 W. Zeng, G. Qiu and M. Chen, Hydrometallurgy, 2013, 134, 158-165.

45 H. Zhao, J. Wang, W. Qin, M. Hu and G. Qiu, Int. J. Electrochem. Sci., 2015, 10, 848-858.

46 W. Qin, C. Yang, S. Lai, J. Wang, K. Liu and B. Zhang, Bioresour. Technol., 2013, 129, 200-208.

47 H. Zhao, J. Wang, M. Hu, W. Qin, Y. Zhang and G. Qiu, Bioresour. Technol., 2013, 149, 71-76.

48 Y. Cai, X. Chen, J. Ding and D. Zhou, Hydrometallurgy, 2012, 113, 109-118.

49 Q. Liu and H. Li, Int. J. Miner. Process., 2011, 98, 82-88. 